\title{
Relation between the coupling and tremor rates in the transition zone around the Shikoku region
}

\author{
Tadafumi Ochi* ${ }^{*}$ and Naoto Takeda
}

\begin{abstract}
We examine the spatiotemporal distributions of the interplate couplings and the tremor count rate in the Shikoku region, which is located in the western part of the Nankai subduction zone in Japan, from July 2007 to June 2015 by comparing the results of static geodetic inversion using onshore global navigation satellite system data and the published tremor catalog. We observe that the temporal fluctuations in these two rates correlated well at a few spotlike points in the tremor-occurrence zone at a deeper location next to the strongly coupled area. The well-correlated points are densely distributed around the long-term slow slip area in the Bungo Channel and are randomly dispersed in the central and eastern portions. The correlation coefficients of the well-correlated points differ from point to point; however, at some points, zero tremor counts can be expected when the coupling rates reach the plate convergence rate. This indicates that tremors occur on the plate interface and that the tremor count rates can be used as proxies for monitoring the small fluctuations in interplate coupling.
\end{abstract}

Keywords: Interplate coupling, Low-frequency tremor, Southwestern Japan

\section{Introduction}

The Shikoku region is located in the western part of the Nankai subduction zone; more specifically, it is located at the boundary between the subducting Philippines Sea plate and the overriding continental plate (Fig. 1). Interactions between the two plates cause great historical earthquakes in intervals of 100-150 years (e.g. Ando 1975; Kumagai 1996) and crustal deformations during interseismic periods. To monitor the crustal deformations, several types of geodetic observations are conducted such as the observations that were conducted using the global navigation satellite system (GNSS), tiltmeter, and strainmeter. The main part of the GNSS observation network is maintained by the Geospatial Information Authority of Japan (GSI), and it is referred to as the GNSS Earth Observation Network (GEONET) (Tsuji et al. 2013). GEONET data not only reveal

\footnotetext{
*Correspondence: tadafumi.ochi@aist.go.jp Geological Survey of Japan, National Institute of Advanced Industrial Science and Technology (AIST), 1-1-1 Higashi, Tsukuba, Ibaraki 305-8567, Japan
}

interplate coupling distributions (e.g. Miyazaki and Heki 2001; Tabei et al. 2007; Loveless and Meade 2010) but also reveal long-term slow slip events (SSEs) that occur during intervals of several years and continue for a period of several months (e.g. Ozawa et al. 2013; Ochi 2015; Yoshioka et al. 2015) in the Bungo Channel, which is located in the western part of the Shikoku region (Fig. 1).

According to the results of Miyazaki and Heki (2001), a strongly coupled area is distributed beneath the Tosa Bay (see Fig. 1) at depths of 20-30 km, and the coupling rates are almost $100 \%$. Yokota et al. (2016) analyzed the offshore Global Positioning System and acoustic ranging (GPS-A) data with the onshore GEONET data and estimated that the coupling distribution extends to the shallower regions and reaches close to the trough. Along with the discussion about spatial distributions, Ochi (2015) estimated the temporal variations in coupling distributions and observed that the long-term SSEs in the area of the Bungo Channel do not affect the coupling rates in the strongly coupled area. Furthermore, they release $30-40 \%$ of the strain on the plate interface that was accumulated between the long-term SSEs in the SSE area. 


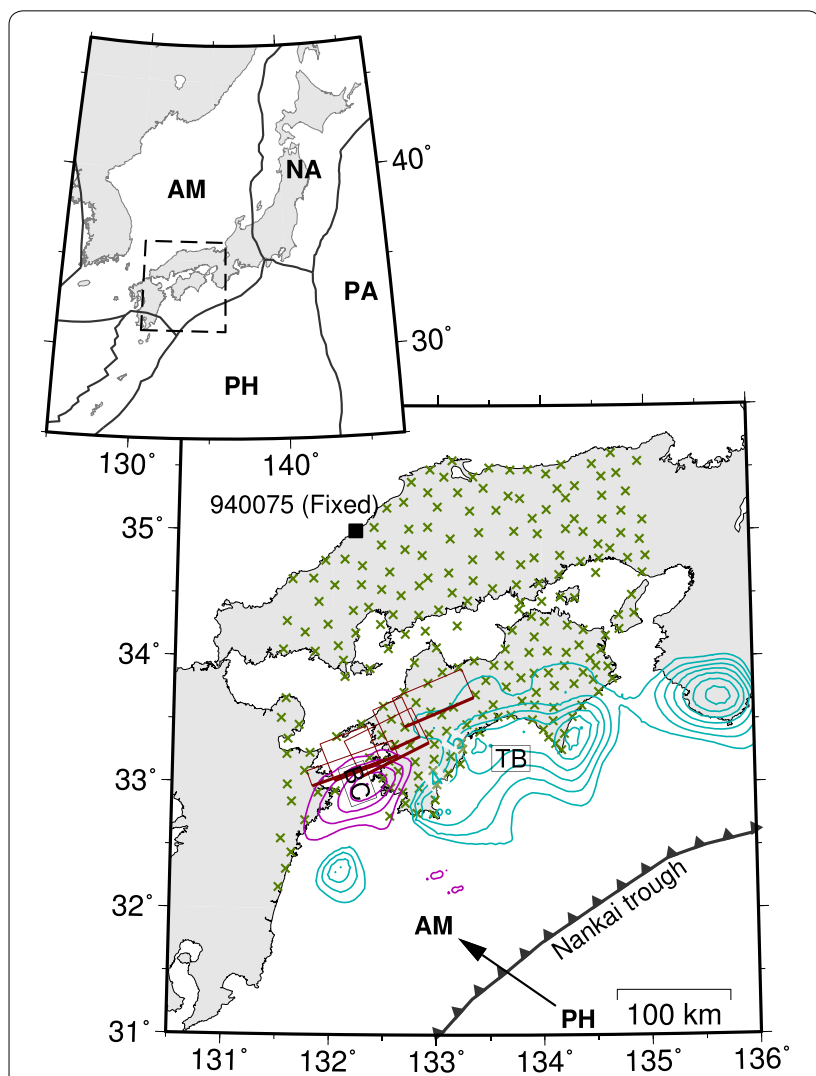

Fig. 1 Tectonic settings around the Shikoku region. Solid lines are the plate boundaries, as per the study by Bird (2003). AM, NA, PA, and $\mathrm{PH}$ denote the Amurian, North American, Pacific, and Philippine Sea plates, respectively. TB and BC denote the Tosa Bay and the Bungo Channel areas, respectively. Small crosses denote the GEONET stations that were used in this study, whereas the black square denotes GEONET 940075, which was used as a fixed point. Blue and red contours show the coupling and the long-term SSE in BC between 2010 and 2011, and dark red rectangles show fault models of the short-term SSE published by Sekine et al. (2010)

In addition to the interplate coupling and the longterm SSEs, the short-term SSEs, whose duration may be of several days, are mainly detected using the tiltmeter data that were maintained by the National Research Institute for Earth and Disaster Resilience (NIED) (e.g. Obara et al. 2004). The short-term SSEs are often observed to coincide spatially and temporally with the deep low-frequency tremors (LFTs), and these phenomena are collectively referred to as an episodic tremor and slip (ETS) (Obara 2010). ETS often occurs in the deeper portions of the subducting plate interface around the depth of $30 \mathrm{~km}$, that is deeper next to the strongly coupled area (Ito et al. 2007). The typical duration of ETS is few days, and the recurrence interval is few months (e.g. Nishimura et al. 2013). In Fig. 1, we also draw coupling and long-term SSE area inferred by Ochi (2015) and rectangular faults of the short-term SSE by Sekine et al. (2010) to show the spatial distribution of these events. Many previous studies discussed spatiotemporal synchronization between SSE and tremor in the subduction zones such as Nankai (e.g. Obara et al. 2004; Hirose and Obara 2010) Cascadia (e.g. Bartlow et al. 2011; Wech and Bartlow 2014), and Hikurangi (e.g. Bartlow et al. 2014).

On the other hand, the SSEs can be regarded as small fluctuations of the coupling rates from the viewpoint of stress accumulation process in the interseismic period (Ochi 2015). The results of Ochi (2015) indicate the occurrence of a few temporal fluctuations in the coupling rate that is observed in the ETS zone. Although the fluctuations in coupling rates in the ETS zone were small, Figure 5 of Ochi (2015) shows that the values exceeded the posterior standard deviation and might be further discussed. Based on this point of view, we re-analyze the GNSS data that was used in Ochi (2015) and compare the coupling rates and LFT rates in the ETS zone. The purpose of this study is to discuss overall spatiotemporal evolution of the coupling and the tremor in the ETS zone regardless of each SSE.

\section{Data and analysis procedure}

To compare the temporal variations of the coupling tremor count rates, we estimated the 1-year averaged coupling rates and counted the number of tremors that were observed during the same period. We considered the average of the values at $t-0.5$ year and $t+0.5$ year to be the value at a time epoch $t$ and incremented $t$ by 0.2 year. The interval that we have examined ranges from January 01, 2007 to December 31, 2016, and the total number of epochs is observed to be 41 .

The data and procedures that are used in this study to estimate the coupling rates are approximately similar to those in Ochi (2015) except for the temporal segmentation. We compiled the daily coordinates of GEONET data that were published as F3 solutions by GSI (Nakagawa et al. 2009) and used three components of the 225 stations that are depicted in Fig. 1. We fitted the following function to the time-series data of the $p$ th component of the $i$ th station in each epoch $k$ :

$$
\begin{aligned}
x_{i, p}(t)= & c_{i, p}^{k}+v_{i, p}^{k} t+A_{i, p} \cos (2 \pi t) \\
& +B_{i, p} \sin (2 \pi t)+C_{i, p} \cos (4 \pi t) \\
& +D_{i, p} \sin (4 \pi t)+\sum_{l} E_{i, p}^{l} H\left(t-t_{l}\right),
\end{aligned}
$$

where $c_{i, p}^{k}$ is a constant offset and $v_{i, p}^{k}$ denotes the mean crustal deformation rate in the epoch $k$. The remaining terms in 1 are as follows: the succeeding four terms correspond to the annual and semiannual variations, whereas the last term $E_{i, p} H\left(t-t_{l}\right)$ corresponds to the 
artificial steps at $t_{l}$ resulting from various actions, such as antenna replacement and tree trimming around the station, as well as the coseismic displacements that were caused due to the Tohoku earthquake, which occurred March 11, $2011\left(M_{\mathrm{JMA}}=9.0\right)$. We estimated $c_{i, p}^{k}, v_{i, p}^{k}$, $A_{i, p}, B_{i, p}, C_{i, p}, D_{i, p}$, and $E_{i, p}$ using a least squares method. The derived velocities $v_{i, p}^{k}$ are converted relative to the velocity values of GEONET 940075 (see Fig. 1).

Using the converted velocities, we perform static geodetic inversion and obtain the coupling rate distributions for all the epochs. In case of inversion analysis, we assume that all the crustal deformations are caused by the slip on the subducting plate interface whose shape is determined by Hirose et al. (2008). The shallowest and deepest ends of the model regions are 4.0 and $62.5 \mathrm{~km}$, respectively, and slip on four sides of the model region are assumed to be zero. Further, we assume that the media is a homogeneous isotropic elastic half space and apply the theoretical crustal deformation due to dislocation, as derived from Okada (1985). In order to stabilize the solutions, we imposed two prior constraints; one is the spatial roughness of slip $r_{1}$ and the other is the total amount of the slip perpendicular to the plate convergence direction $r_{2} . r_{1}$ and $r_{2}$ are defined by the following equations;

$$
\begin{aligned}
& r_{1}=\int_{\Sigma}\left\|\nabla^{2}(\Delta u)\right\|^{2} \mathrm{~d} \Sigma, \\
& r_{2}=\int_{\Sigma}\left\|\Delta u_{\perp}\right\|^{2} \mathrm{~d} \Sigma,
\end{aligned}
$$

where $\Delta u$ is slip (coupling) amount on the plate interface, $\Delta u_{\perp}$ is the slip component perpendicular to the plate convergence direction $\mathrm{N} 55^{\circ} \mathrm{W}$, which was determined by Miyazaki and Heki (2001), and $\nabla^{2}$ is a Laplacian along the curved fault surface $\Sigma$, respectively. The observation equations are solved together with the constraint equations $r_{1}=0$ and $r_{2}=0$. The contributions of two constraint equations are determined by using $\mathrm{ABIC}$ criterion methods defined by Ito and Hashimoto (2004).

Three examples of the inferred coupling distributions are depicted in Fig. 2. Blue and red contours represent the normal and reverse slip areas, i.e. the interplate coupling and slow slip areas, respectively. To locally discuss the relation between the coupling rates and tremor count rates, we divide the area in which the tremors were detected into small grids with side lengths of $0.1^{\circ}$ in terms of latitude as well as longitude (see Fig. 2).

The tremor data, which are depicted in Fig. 2 as well, are extracted from the NIED tremor catalogue (Obara 2010; Maeda and Obara 2009; Obara et al. 2010). Finally, we count the number of detected tremors in each grid and each epoch that was set during the inversion analysis to determine the coupling rate distributions for comparing the tremor activity with the coupling rate.

\section{Results}

To discuss the relation between the coupling and tremor count rates, we select five grids that were distributed evenly over the ETS zone, as depicted in Fig. 2, and obtain the time series of the coupling rates and the tremor count rates as shown in the upper panels of Fig. 3. In order to emphasize the relation, each lower panel in Fig. 3 shows the scaled and shifted time series of the coupling rates to fit the time series of the tremor count rate. The noticeable decrease in the coupling rate at grid A around 2010 and 2011 corresponds to the longterm SSE that was observed in the Bungo Channel from 2009.5 to 2011.2 (Yoshioka et al. 2015), which is marked

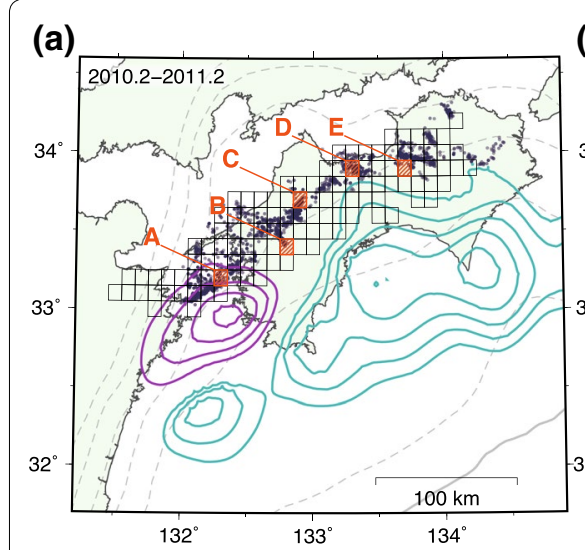

(b)

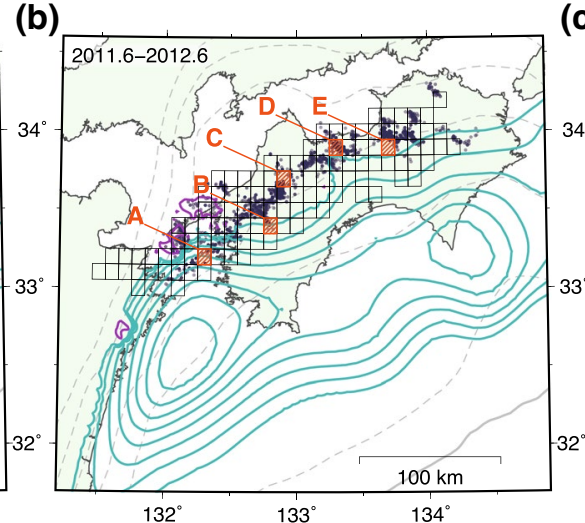

(c)

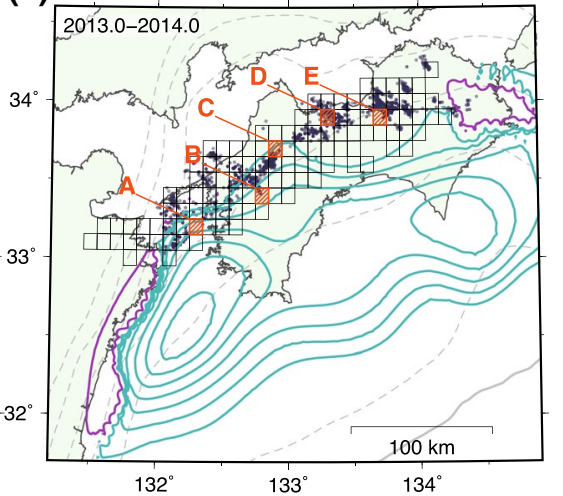

Fig. 2 Examples of coupling distributions (solid contours) at 3 of the 41 epochs with epicenters of tremor in the same epoch. $\mathbf{a}$, $\mathbf{b}$ and $\mathbf{c}$ show the distributions in 2010.2-2011.2, 2011.6-2012.6, and 2013.0-2014.0, respectively. The blue and red contours represent the positive and negative coupling rates, respectively, and the negative coupling rates correspond to slow slips. Spacings of the contours are 1 and $3 \mathrm{~cm} / y e a r$ for the positive and negative values, respectively. Blue dots denote the epicenters of the tremors, and black grids are used for analyzing the relation between the coupling and the tremor count rates. Grids A-E correspond to the results that are depicted in Figs. 3 and 5 

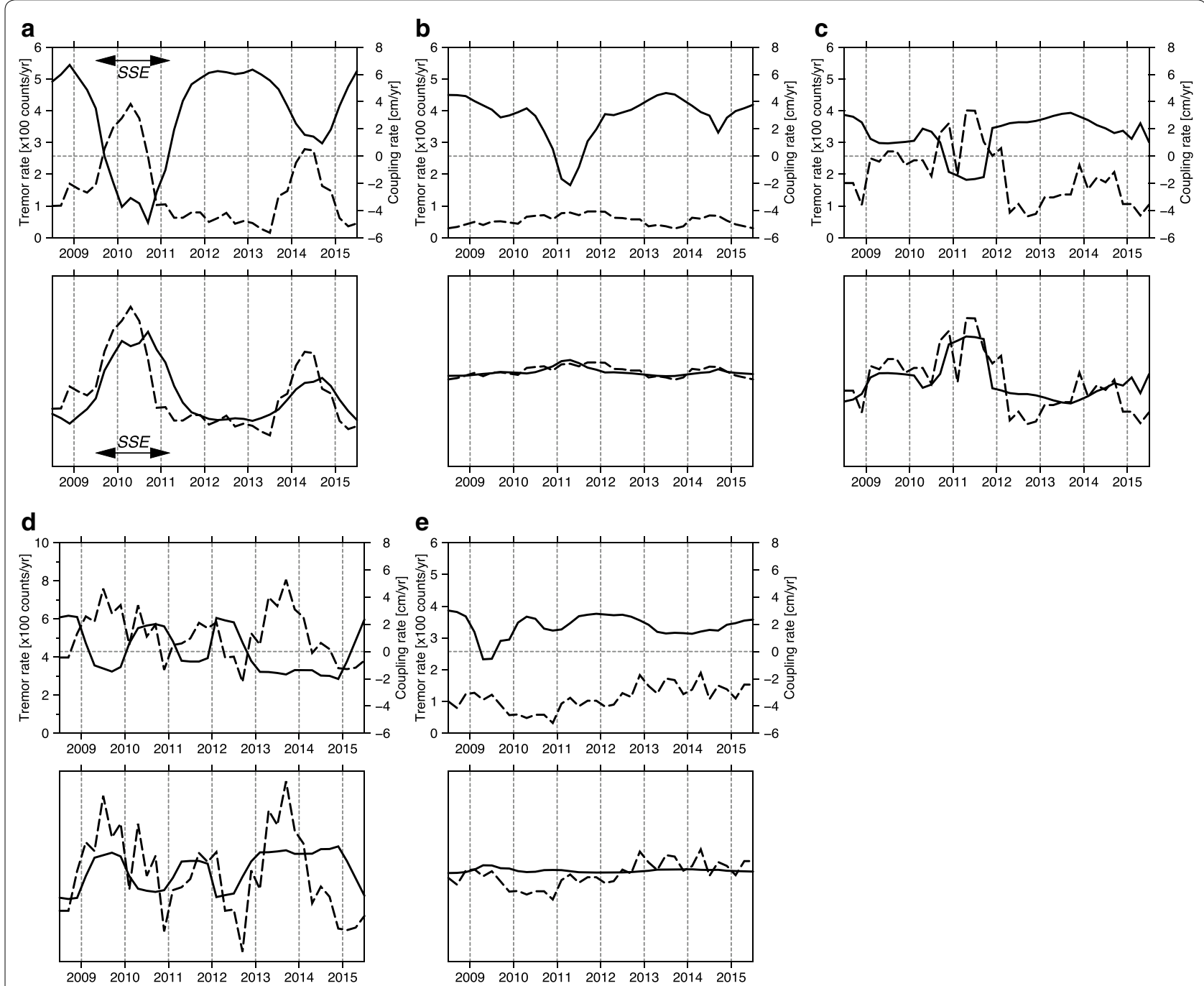

Fig. 3 (Upper panels) Time series of the coupling rates (solid lines and right axes) and the tremor count rates (dashed lines and left axes). a-e correspond to the values at grids (A)-(E) in Fig. 2. (Lower panels) Scaled time series of the coupling rates (solid lines) to fit the time series of the tremor count rates (dashed lines), which are identical to those that are depicted in the corresponding upper panels. The vertical scales are the same in the five upper panels, except for $\mathbf{d}$, and in the five lower panels. "SSE" in $\mathbf{a}$ is the period of long-term SSE from 2009.5 to 2011.2, that was mentioned in Yoshioka et al. 2015

"SSE" in Fig. 3a and is coincident with the increase in the tremor count rate. Temporal synchronization between the tremor count rate and the long-term SSE was already mentioned by Hirose et al. (2010). The decrease in the coupling rate and increase in the tremor count rate are observed around 2014 as well, and they correspond to another long-term SSE.

In addition to these two long-term SSEs, there are fluctuations in both the coupling and the tremor count rates in grids $\mathrm{B}-\mathrm{E}$, and a few reverse synchronizations can be observed. As is the case in grid A, the upper panels of Fig. 3b, c may depict reverse synchronization between the coupling and the tremor count rates in grids $B$ and $C$.
Although the tremor count rates in grid B is not as active as those in grid $\mathrm{A}$, increases in the tremor count rates can be observed corresponding to the decreases in the coupling rates during 2010-2012 and at the end of 2014. The tremor count rate in grid $\mathrm{C}$ depicts a few short-period fluctuations around 2010-2012 and 2014-2015; however, the overall increase and decrease were observed to be synchronized with the decrease and increase in the coupling rate, respectively.

However, we can observe little reverse synchronization between the coupling and the tremor count rates in grids $\mathrm{D}$ and $\mathrm{E}$. In grid $\mathrm{D}$, the tremor count rates exhibit considerably shorter period fluctuations than those in grid 
C; however, the coupling rates do not exhibit such fluctuations. Identical short-period fluctuations are observed in grid E during the latter half; however, after 2012.5, we can observe a few reverse synchronizations in the former half.

To verify and obtain the spatial distributions of the relation between the coupling and the tremor count rates, we calculated the correlation coefficients for all the samples at all the grid points (Fig. 4). In this step, we treat the values of the coupling and the tremor count rate at each time step as two-dimensional data and calculated the correlations through variances of each rate and a covariance between them. It is known that the correlation is high around the long-term SSE region and that the high correlation coefficient in grid $\mathrm{A}$ is trivial. In addition to grid $\mathrm{A}$, there are a few spot-like high correlation grids such as grids $\mathrm{B}$ and $\mathrm{C}$. This may indicate a few boundary conditions between the Philippine Sea plate and the continental plate.

\section{Discussion}

Figure 5 illustrates the scatter plot between the tremor count rates and the coupling rates for all the samplings at grids $\mathrm{A}-\mathrm{C}$, where the correlations mentioned above are strong. The dashed lines in Fig. 5 are the linear regression lines.

$$
y=\alpha x+\beta
$$

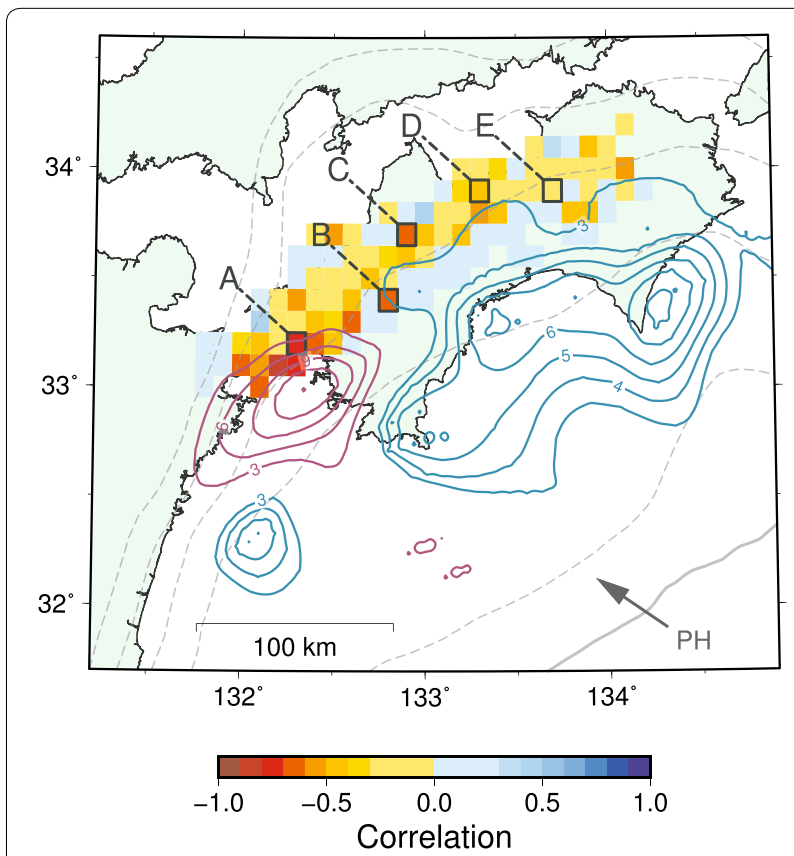

Fig. 4 Correlation coefficients between the coupling and tremor count rates in each grid. Red and blue contours are the same as in Fig. 1

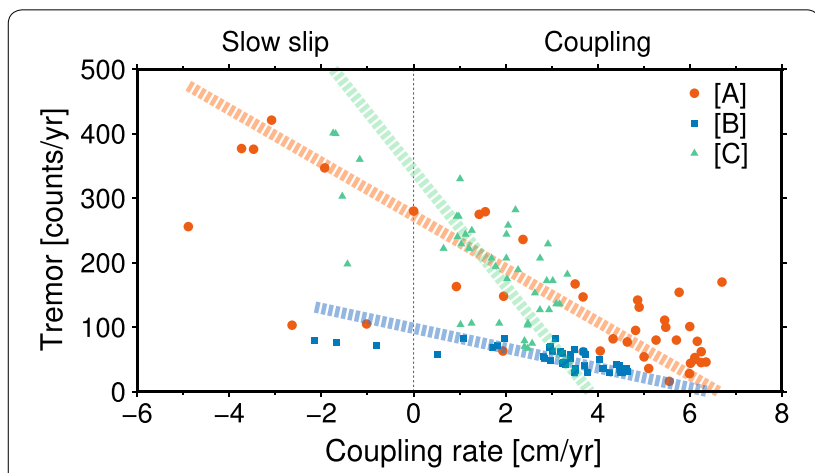

Fig. 5 Scatter plot of the coupling and tremor count rates at grids A-C that is depicted in Fig. 2 for all the 41 epochs between 2007.5 and 2015.5. Bold dashed lines denote the regression lines of the plots having the same color

where $x$ and $y$ are the coupling and tremor count rates, respectively, and the coefficient $\alpha$ and the intercept $\beta$ are determined to minimize the sum of the squared distances perpendicular to the regression line from the data points. The values of $\alpha$ for grids $\mathrm{A}-\mathrm{C}$ are $-41.2,-15.3$, and -89.7 counts/cm, respectively. Therefore, the conversion factor between the coupling and the tremor count rates is observed to vary by location even though the correlations may be strong.

Because the recurrence interval of the short-term SSEs in the same area is less than one year, the 1-year averaged tremor count does not drop to zero and always depicts a positive value. However, if the three regression lines in Fig. 5 are extended to the coupling axis where the tremor count is zero, the lines of grids A-C cross the coupling axis at $6.6,6.4$, and $3.8 \mathrm{~cm} /$ year (depicted by the dashed lines in Fig. 5), respectively. The values of grids A and B are almost equal even though the grids are not adjacent, and the values are not much different from $7 \mathrm{~cm} /$ year, which represents the plate convergence rate in this region (Miyazaki and Heki 2001).

As shown in Fig. 4, there are many well-correlated grids other than the grids $\mathrm{A}-\mathrm{C}$. If the grids where the correlations are less than -0.6 (9 grids) or -0.5 ( 14 grids) are selected, the average coupling rates at the zero tremor count rate expected by the same regression above are $5.6 \pm 1.2$ or $4.6 \pm 1.9 \mathrm{~cm} /$ year, respectively. Although the standard deviations are comparatively large, this result indicates that low-frequency tremors cannot occur during the condition of full coupling and that the hypocenters of the tremor are located at the plate interface. This investigation cannot be applied to the results of grid $\mathrm{C}$ because $3.8 \mathrm{~cm} /$ year is too small to represent the plate convergence rate. It should be noted that the result of grid C, $3.8 \mathrm{~cm} /$ year, is smallest among the 9 selected grids mentioned above, and the data points in grid $\mathrm{C}$ seem to 
be well fit by the regression line for the grid A (Fig. 5) but some outlier or offset may cause the results quite different.

Obara (2010) examined the number of tremors and short-term SSEs in southwestern Japan and observed that a few tremor events were not associated with shortterm SSEs owing to the detection limit of the SSEs. They divided the study area into small segments that were defined by tremor gaps along the strike direction of the subducting plate, discussed the tremor events with and without short-term SSEs, and derived the relation between the tremor counts and the amount of slip of the corresponding short-term SSE. Using the relation, they presented the temporal evolution of the cumulative slip histories in each region.

We analyzed the relation between the tremor count and the coupling rates in a two-dimensional manner and observed that the correlations vary not only along the strike direction but also along the dip direction of plate subduction (Fig. 4). Because the segments in Obara (2010) are larger than the grids in our study, the slip history in Obara (2010) is observed to be spatially averaged. Although the fluctuations of the coupling rate in our study reflect the sum of short-term SSEs in each epoch, we cannot resolve the fluctuations into individual SSEs. This indicates that the spatial and temporal resolutions are complementary.

The other problem is a change of the detection level for the tremor because the analyzed duration in this study reaches 7 years. We assume that the detection level is constant and do not further considered this matter because the seismic network for detecting tremor does not change drastically in this period.

\section{Conclusion}

In this study, we focus on the temporal evolution of the interplate coupling in Shikoku region and infer it using daily GNSS data. We do not focus on each SSE but regard the temporal change of the coupling rate as fluctuations of strain accumulation in the interseismic period, and we find some fluctuations of the coupling rate in the ETS zone at a region underneath the strongly coupled area. The fluctuation of the coupling is correlated with the tremor count rates at the same area in some spot-like points, and the points locate not only around the longterm SSE area but also in the other area in the ETS zone. The fluctuations may reflect superposition of some shortterm SSEs, but it is not clear due to the lack of temporal resolution of this study. Instead, we show the spatial heterogeneity of the correlations between the coupling and tremor activity that was spatially smoothed and regarded as the faults of short-term SSE in the previous studies. This result may reflect a few physical aspects, such as plate shapes, thermal conditions, or friction properties. The procedure of this study can be adopted to other subduction zones. Comparing the results in many subduction zone will overcome the problem of physical aspects.

\section{Authors' contributions}

TO analyzed the data and wrote the paper. NT verified and discussed the results. Both authors read and approved the final manuscript.

\section{Acknowledgements}

The GNSS data that were used in this study were provided by GSI, and the tremor data were obtained from NIED tremor catalogue through "Slow Earthquake Database" (Kano et al. 2018) that was supported by JSPS KAKENHI Grant No. JP16H06472 in Scientific Research on Innovative Areas "Science of Slow Earthquakes."We used the Generic Mapping Tools (GMT) to draw figures. We also thank the anonymous reviewers for their helpful comments and suggestions to improve the manuscript.

\section{Competing interests}

The authors declare that they have no competing interests.

\section{Availability of data and materials}

The daily GNSS coordinate data and the tremor hypocenter catalog are available from GSI web site (http://terras.gsi.go.jp) and "Slow Earthquake Database" (http://www-solid.eps.s.u-tokyo.ac.jp/ sloweq/), respectively.

\section{Funding}

The submission of the manuscript was funded by Geological Survey of Japan, National Institute of Advanced Industrial Science and Technology (AIST).

\section{Publisher's Note}

Springer Nature remains neutral with regard to jurisdictional claims in published maps and institutional affiliations.

Received: 16 March 2018 Accepted: 26 June 2018

Published online: 11 July 2018

\section{References}

Ando M (1975) Source mechanisms and tectonic significance of historical earthquakes along the Nankai Trough, Japan. Tectonophysics 27(2):119140. https://doi.org/10.1016/0040-1951(75)90102-X

Bartlow NM, Miyazaki S, Bradley AM, Segall P (2011) Space time correlation of slip and tremor during the 2009 Cascadia slow slip event. Geophys Res Lett 38(L18):309. https://doi.org/10.1029/2011GL048714

Bartlow NM, Wallace LM, Beavan JR, Bannister S, Segall P (2014) Time-dependent modeling of slow slip events and associated seismicity and tremor at the hikurangi subduction zone, New Zealand. J Geophys Res Solid Earth 119(1):734-753. https://doi.org/10.1002/2013JB010609

Bird P (2003) An updated digital model of plate boundaries. Geochem Geophys Geosyst 4(3):1027. https://doi.org/10.1029/2001GC000252

Hirose F, Nakajima J, Hasegawa A (2008) Three dimensional seismic velocity structure and configuration of the Philippine Sea slab in southwestern Japan estimated by double difference tomography. J Geophys Res 113(B9):B09315. https://doi.org/10.1029/2007JB005274

Hirose H, Obara K (2010) Recurrence behavior of short-term slow slip and correlated nonvolcanic tremor episodes in western Shikoku, southwest Japan. J Geophys Res Solid Earth 115(B6):B00A21. https://doi. org/10.1029/2008JB006050

Hirose H, Asano Y, Obara K, Kimura T, Matsuzawa T, Tanaka S, Maeda T (2010) Slow earthquakes linked along dip in the Nankai subduction zone. Science 330(6010):1502-1502

Ito T, Hashimoto M (2004) Spatiotemporal distribution of interplate coupling in southwest Japan from inversion of geodetic data. J Geophys Res 109(B2):B02315. https://doi.org/10.1029/2002JB002358 
Ito Y, Obara K, Shiomi K, Sekine S, Hirose H (2007) Slow earthquakes coincident with episodic tremors and slow slip events. Science 315(5811):503-506. https://doi.org/10.1126/science.1134454

Kano M, Aso N, Matsuzawa T, Ide S, Annoura S, Arai R, Baba S, Bostock M, Chao K, Heki K, Itaba S, Ito Y, Kamaya N, Maeda T, Maury J, Nakamura M, Nishimura T, Obana K, Ohta K, Poiata N, Rousset B, Sugioka H, Takagi R, Takahashi T, Takeo A, Tu Y, Uchida N, Yamashita Y, Obara K (2018) Development of a Slow Earthquake Database. Seismological Research Letters 89(4):1566-1575

Kumagai H (1996) Time sequence and the recurrence models for large earthquakes along the Nankai Trough revisited. Geophys Res Lett 23(10):11391142. https://doi.org/10.1029/96GL01037

Loveless JP, Meade BJ (2010) Geodetic imaging of plate motions, slip rates, and partitioning of deformation in Japan. J Geophys Res 115(B2):B02410. https://doi.org/10.1029/2008JB006248

Maeda T, Obara K (2009) Spatiotemporal distribution of seismic energy radiation from low frequency tremor in western Shikoku, Japan. J Geophys Res Solid Earth 114(B10):B00A0. https://doi.org/10.1029/2008JB006043

Miyazaki S, Heki K (2001) Crustal velocity field of southwest Japan: subduction and arc-arc collision. J Geophys Res 106(B3):4305-4326. https://doi. org/10.1029/2000JB900312

Nakagawa H, Toyofuku T, Kotani K, Miyahara B, Iwashita C, Kawamoto S, Hatanaka Y, Munekane H, Ishimoto M, Yutsudo T, Ishikura N, Sugawara Y (2009) Development and validation of GEONET new analysis strategy (version 4). J Geospatial Inf Auth Jpn 118:1-8

Nishimura T, Matsuzawa T, Obara K (2013) Detection of short-term slow slip events along the nankai trough, southwest Japan, using GNSS data. J Geophys Res 118:3112-3125. https://doi.org/10.1002/jgrb.50222

Obara K (2010) Phenomenology of deep slow earthquake family in southwest Japan: spatiotemporal characteristics and segmentation. J Geophys Res Solid Earth 115(B8):B00A25. https://doi.org/10.1029/2008JB006048

Obara K, Hirose H, Yamamizu F, Kasahara K (2004) Episodic slow slip events accompanied by non volcanic tremors in southwest Japan subduction zone. Geophys Res Lett 31:L23602. https://doi.org/10.1029/2004GL0208 48

Obara K, Tanaka S, Maeda T, Matsuzawa T (2010) Depth-dependent activity of non-volcanic tremor in southwest Japan. Geophys Res Lett 37(L13):306. https://doi.org/10.1029/2010GL043679

Ochi T (2015) Temporal change in plate coupling and long-term slow slip events in southwestern Japan. Earth Planet Sci Lett 431:8-14. https://doi. org/10.1016/j.epsl.2015.09.012

Okada Y (1985) Surface deformation due to shear and tensile faults in a halfspace. Bull Seismol Soc Am 75(4):1135-1154

Ozawa S, Yarai H, Imakiire T, Tobita M (2013) Spatial and temporal evolution of the long-term slow slip in the Bungo Channel, Japan. Earth Planets Space 65(2):67-73. https://doi.org/10.5047/eps.2012.06.009

Sekine S, Hirose H, Obara K (2010) Along strike variations in short term slow slip events in the southwest Japan subduction zone. J Geophys Res Solid Earth 115(B9):B00A27. https://doi.org/10.1029/2008JB006059

Tabei T, Adachi M, Miyazaki S, Watanabe T (2007) Interseismic deformation of the Nankai subduction zone, southwest Japan, inferred from threedimensional crustal velocity fields. Earth Planets Space 59:1073-1082. https://doi.org/10.1186/BF03352050

Tsuji H, Miyagawa K, Yamaguchi K, Yahagi T, Oshima K, Yamao H, Furuya T (2013) Modernization of GEONET from GPS to GNSS. Bull Geospatial Inf Auth Jpn 61(12):9-20

Wech AG, Bartlow NM (2014) Slip rate and tremor genesis in Cascadia. Geophs Res Lett 41(2):392-398. https://doi.org/10.1002/2013GL058607

Yokota Y, Ishikawa T, Watanabe S, Tashiro T, Asada A (2016) Seafloor geodetic constraints on interplate coupling of the Nankai Trough megathrust zone. Nature 534:374-377. https://doi.org/10.1038/nature17632

Yoshioka S, Matsuoka Y, Ide S (2015) Spatiotemporal slip distributions of three long-term slow slip events beneath the Bungo Channel, southwest Japan, inferred from inversion analyses of GPS data. Geophys J Int 201(3):1437-1455. https://doi.org/10.1093/gji/ggv022

\section{Submit your manuscript to a SpringerOpen ${ }^{\circ}$ journal and benefit from:}

- Convenient online submission

- Rigorous peer review

- Open access: articles freely available online

- High visibility within the field

Retaining the copyright to your article

Submit your next manuscript at $\boldsymbol{\nabla}$ springeropen.com 